\section{MÚSICA, COTIDIANIDAD E IDENTIDADES COLECTIVAS EN EL CINE DE AGNĖS JAOUI}

\author{
Teresa Fraile Prieto \\ Universidad de Extremadura \\ tefraile@unex.es \\ fraileteresa@hotmail.com
}

\section{MUSIC, EVERYDAY LIFE AND COLLECTIVE IDENTITIES IN AGNĖS JAOUI'S FILMS}

\begin{abstract}
RESUMEN: El cine de la directora y actriz francesa Agnès Jaoui hace un retrato de la burguesía contemporánea del contexto francés en un tono mordaz e irónico. Bajo la apariencia de comedias dramáticas, sus películas plantean narrativas corales que sacan a la luz la dificultad de las relaciones humanas, las hipocresías y las paradojas de la sociedad occidental, al tiempo que son una reflexión sobre los discursos identitarios de la Francia actual. Además, la biografía de Jaoui presenta una estrecha relación con la música que se ve plasmada en sus películas, convirtiéndose en un factor fundamental de la trama y en un medio expresivo de primer orden en sus producciones. Este artículo aborda el estudio de todos estos elementos constructivos y su relación con la realidad francesa en los largometrajes Le goût des autres (Para todos los gustos, 2000), Comme une image (Como una imagen, 2004), y Parlez-moi de la pluie (Háblame de la lluvia, 2008).
\end{abstract}

PALABRAS CLAVE: Cine francés contemporáneo, identidad colectiva, música.

\section{Agnès Jaoul en el cine francés Contemporáneo}

A lo largo de su desarrollo histórico, el cine francés ha fortalecido la imagen de un cine de tendencia realista, que es capaz de hablar de los problemas sociales y políticos, que reflexiona sobre las reglas de la sociedad, y que se inmiscuye en la interioridad de personajes tomados de los entornos más cotidianos. Existe la tendencia, también, a pensar en el cine francés como un cine de auteur, donde las obras están firmadas por las especificidades estéticas que le confieren sus artífices. En este sentido, las películas de la guionista, directora y actriz Agnès Jaoui seguramente cumplen las expectativas de cualquier espectador que se acerque al cine a ver una obra de características francesas.

Sin embargo, como veremos en estas líneas, el cine de Jaoui es eso y mucho más, puesto que se introduce en su cotidianidad adyacente para ponerla en tela de juicio

\begin{abstract}
The films of Agnès Jaoui, a French filmmaker and actress, take an ironic and incisive view of the contemporary French bourgeoisie. Under the guise of dramatic comedies, her films offer polyphonic narratives underlining the difficulties of human relationships, the hypocrisies and the paradoxes of Western societies, as well as constituting a reflection upon identity discourses in present-day France. Jaoui's biography is also closely linked to music, which comes accross in her films; and music becomes a fundamental element in the plot and a crucial means of expression. This paper analyses all these building blocks and their relation to the reality of France in the following films: Le goût des autres (2000), Comme une image (2004), and Parlez-moi de la pluie (2008).
\end{abstract}

KEY WORDS: Contemporary French cinema, collective identity, music.

y cuestionar sus normas, pero también añade conceptos de absoluta contemporaneidad que no podrian formularse sino en las sociedades del siglo XXI, al tiempo que ha conseguido situarse como una de las autoras más vistas dentro y fuera de las fronteras galas.

$Y$ es que pensar el cine francés, y por extensión el cine europeo, como un cine para minorías, plagado de temas de reflexión interior y denuncia sobrentendida, peca de un reduccionismo exagerado. En su libro Popular Cinemas of Europe, Dimitris Eleftheriotis (2001) cuestiona la existencia de una definición válida de cine europeo y de los diferentes cines nacionales. Según este autor, los discursos políticos que han sostenido la idea de Europa defienden la existencia de una cultura común amparada en acontecimientos del pasado que van desde el Imperio Romano hasta la Ilustración, la Revolución francesa o el desarrollo industrial, pero cuya centralidad, así como la exclusión de otros 
procesos históricos, ha sido criticada duramente por las tendencias postcolonialistas. Esta crítica a los cimientos de la idea de Europa da lugar a una continua reflexión y a una marcada autocrítica, un rasgo también muy europeo, al mismo tiempo que conduce a la defensa de una declarada diversidad cultural. De ahí que la diversidad y la autocrítica sean una característica clara de las cinematografías que englobamos dentro del cine europeo, incluido el francés.

Así pues, el cine francés contemporáneo es plural y resulta de la suma de diversas tendencias. Es deudor, como no podría ser de otra manera, de la Nouvelle vague, aquella célebre renovación estética hecha por jóvenes de la que trascendieron nombres como François Truffaut, Jean-Luc Godard, Alain Resnais, Claude Chabrol, Éric Rohmer, Jacques Rivette, Jean-Pierre Melville o Agnès Varda, cuya pretensión fue deshacerse de las trabas sociales y morales del cine anterior, y que se permitieron ser apolíticos cuando la situación histórica pedía justamente lo contrario. La generación de los noventa se puede interpretar como una generación que rescata rasgos de la Nouvelle vague, en el sentido de que mira hacia entornos cercanos a los propios autores y retrata sus realidades más próximas. Asimismo, puede identificarse un grupo de películas caracterizadas por la implicación social, algunas de las cuales retratan la Francia de provincias o las banlieues de las grandes ciudades, otras se acercan a los actuales problemas identitarios y de exclusión social, y otras se aproximan a estas temáticas en tono de comedia. El cine francés actual es variado, y a la "nouvelle nouvelle vague" se le une el cine de vocación internacional más cercano en temática y factura al norteamericano.

Igual que en España, los años noventa franceses son un estallido de nuevos cineastas, beneficiados igualmente por las ayudas a jóvenes realizadores que provienen de las instituciones, de ahí que lleguen a las pantallas francesas géneros de lo más diverso encarnados en las películas de autores tan distintos como Luc Besson, André Téchiné, Alain Corneau, Mathieu Kassowitz, Christophe Gans, Olivier Assayas, Benoît Jacquot, Bruno Dumont o Robert Guédiguian. Al mismo tiempo, por razones político-sociales evidentes, desde los años setenta el número y la importancia de las directoras francesas aumenta de forma destacada, así que progresivamente vamos pudiendo hablar del cine francés como cine de autores y de autoras. A nombres históricos tan conocidos como Germaine Dulac, Marguerite
Duras o Agnès Varda, en el cine francés contemporáneo debemos sumar a la dirección otros nombres femeninos: Noémie Lvovsky, Émilie Deleuze, Tonie Marshall, Chantal Akerman, Catherine Breillat, Claire Denis, Coline Serreau, Josiane Balasko, Julie Delphy, Marion Vernoux, Laetitia Masson, Virginie Despentes, Claire Simon, Pascale Ferran, Sandrine Veysset o Dominique Cabrera, solo por citar algunos. Agnès Jaoui, por su popularidad, ocupa un lugar de honor en esta relación.

Otro factor fundamental, que no deja de tener su importancia al hablar del cine de esta autora, consiste en que el cine francés se ve masivamente en las pantallas francesas, es un producto habitualmente consumido. Gracias al modelo de financiación pública, todas las cadenas de televisión programan cine nacional, lo que permite obtener una recaudación que revierte en la producción y mantiene una cinematografía subvencionada de más de 200 películas al año. Esto la coloca muy por encima de cualquier otra industria europea, pero también influye en la realización de filmes localizados en ambientes franceses, pues a los espectadores les gusta reconocerse en esas películas.

Las películas realizadas por Agnès Jaoui, por lo tanto, seguirian estas pautas de diversidad, autocritica social, pluralidad, observación de realidades próximas y personajes con los que el público francés se siente identificado. Hasta cierto punto, actualiza la línea de un cine francés tradicional, es decir, un cine de autor (que además actúa y dirige sus guiones), con narrativas situadas en contextos realistas, de introspección y de personajes, un cine no político pero sí comprometido culturalmente con su entorno, situado a medio camino entre la saga de Éric Rhomer Contes des quatre saisons y los musicales (Todos dicen I Love You) de Woody Allen.

\section{Un retrato de Agnès Jaoul}

Aunque Agnès Jaoui nació en 1964 en Antony, Hauts-deSeine (Francia), es de ascendencia judia tunecina, hija de un asesor comercial y una psicoterapeuta. Sus primeros pasos en el mundo de la interpretación los dio en 1984, cuando asistió a clases de interpretación en el Teatro de los Amandiers de Nanterre, dirigido por Patrice Chéreau. Un año antes, había hecho su primera aparición en el cine 
en Le Faucon (1983) de Paul Boujenah y más adelante, en 1987, aparecerá en Hôtel de France, dirigida por el propio Chéreau.

Ese mismo año tuvo lugar un hecho determinante en su vida y en su carrera: en el ámbito del teatro, interpretando L'Anniversaire de Harold Pinter (The Birthday Party, en el original), conoció a su colaborador y compañero JeanPierre Bacri. A partir de entonces su vida sentimental y su trabajo han ido ligados a Bacri, quien aparece como intérprete en sus películas y con quien coescribe los guiones. Surge el tándem Jaoui-Bacri, los Jacri, como los llamó Alain Resnais ("La francesa Agnès Jaoui estrena el viernes Para todos los gustos"), y aunque es Agnès Jaoui la que rueda sus películas, escriben textos a cuatro manos desde que hicieran en 1989 la obra de teatro Cuisine et dépendances (Platos combinados), estrenada en septiembre de 1991 y posteriormente adaptada a la gran pantalla en la película de Philippe Muy (1993). El enorme éxito que obtuvo Cuisine et dépendances (de hecho ganó un premio Molière al mejor texto teatral) supuso el despegue de la carrera de esta autora.

La faceta de guionista y de autora de teatro resulta fundamental para entender la personalidad de Jaoui. Es escribiendo historias donde más a gusto se encuentra y de donde deriva la fuerza de sus historias, que son a su vez la clave para comprender su cine. Precisamente, la importancia del teatro en la vida de Jaoui no radica solamente en que suponga sus inicios en el mundo de la creación y la manera en la que empieza a ganarse la vida, sino sobre todo en que sus películas tienen un gran sesgo teatral. Si bien a medida que avanza su producción cinematográfica los movimientos visuales se hacen progresivamente más ricos y el lenguaje cinematográfico menos teatral, continúa internamente el lazo con el mundo del teatro en la temática y en el tratamiento de los personajes. Esa huella se percibe en la elección de pocos personajes, en la abundancia de diálogos, en la presencia de silencios, en las actitudes, en lo dicho y lo no dicho, en la importancia que concede a las relaciones entre personajes. Al mismo tiempo, la ambientación suele situar las secuencias en escenarios concretos, casi siempre reduciendo los lugares a unos pocos, incluso, como en Parlez-moi de la pluie, a una única casa donde se gestan y se resuelven los conflictos entre protagonistas.
Además, en sus películas la teatralidad pone de manifiesto el carácter teatral de algunos rituales de la vida social, por lo que la forma misma refuerza el contenido de la narración. Ya que a menudo recurre a mostrar en sus ficciones la construcción de los espectáculos y el backstage, tanto del mundo del teatro como del ámbito de la música, esto le permite establecer paralelismos entre la construcción de la vida social (fiestas, inauguraciones de exposiciones, comidas entre amigos, etc.) y la del espectáculo (conciertos, obras de teatro).

Antes de acometer la dirección, Jaoui trabajó con éxito en el guión de otra serie de producciones. Tras Cuisine et dépendances, realizó junto a Bacri la adaptación del ciclo de obras Intimate Exchanges, del dramaturgo inglés Alan Ayckbourn, para la película de Alain Resnais Smoking / No Smoking (1993), ganadora del César al mejor guión. Su segunda obra teatral, Un air de famille (Como en las mejores familias), que también fue llevada al cine por el director Cédric Klapisch en 1996, supuso el reconocimiento de Jaoui y Bacri y una rotunda consagración al ganar el César al mejor guión y aportar a Agnès Jaoui una nominación al mejor papel secundario femenino. La pareja volvió a colaborar de nuevo con Alain Resnais en 1997 como guionistas e intérpretes en la comedia-musical On connaît la chanson, a su vez ganadora de dos César en las mismas categorías.

Respecto a su faceta como actriz, aparece asiduamente en los proyectos donde ejerce la labor de guionista y de dirección, pues actuar es una de sus perspectivas creativas favoritas, de la que no se puede desprender, y porque tiene confianza en sí misma en este aspecto. Además, ha actuado en Canti (1991) de Manuel Pradal, en Le déménagement (1997) de Olivier Doran, en el cortometraje La méthode (1997) de Thomas Béguin, en Le cousin (1998) de Alain Corneau o en On the Run (1999), de Bruno de Almeida. Su ratificación interpretativa vino al realizar los papeles protagonistas en Une femme d'extérieur (1999) de Christophe Blanc, 24 heures de la vie d'une femme (2002) de Laurent Bouhnik, Le rôle de sa vie (2004) de François Favrat y La maison de Nina (2005) de Richard Dembo.

En el año 2000 empieza su carrera como directora en Le goût des autres (Para todos los gustos). Aunque fue su ópera prima, además de ser candidata al Óscar a la mejor película en lengua extranjera, fue galardonada con numerosos premios, entre ellos el premio René Clair y dos César en las categorías de mejor película y mejor guión, 
al tiempo que ganó el premio a mejor guionista en los European Film Awards de 2001. A Le goût des autres le siguió Comme une image (Como una imagen, 2004), que en el Festival de Cannes fue nominada a la Palma de Oro y ganó el premio al mejor guión, en los premios César fue nominada al mejor guión, y en los European Film Awards ganó el premio al mejor guionista y fue nominada al mejor director. Posteriormente dirigió su tercera película Parlezmoi de la pluie (Háblame de la lluvia, 2008).

\section{LAS PELÍCULAS}

Creo que todas mantienen un punto en común. Todas hablan del orgullo, de los prejuicios, de la fuerza de las formas y apariencias sobre nuestras vidas. Hablan de la dificultad de vivir la vida, de no seguir un camino preparado y ordenado por nuestros orígenes socioculturales. También hablan de los malentendidos entre las personas porque aunque pensamos que conocemos a los otros, en realidad muchas veces no nos conocemos ni a nosotros mismos ("Entrevista a la directora francesa Agnès Jaoui").

Con estas palabras sintetiza Agnès Jaoui las líneas maestras de las películas que ha dirigido hasta la fecha, abordando temas que son recurrentes en sus guiones desde la primera obra de teatro que escribió con Bacri. A grandes rasgos, en sus obras une la reflexión sobre las realidades sociales con la reflexión sobre el comportamiento humano.

El comportamiento de los personajes es el factor que los hace crecer por momentos a ojos de los espectadores, pues las personalidades simples se vuelven complejas a medida que avanza la película, demostrando así la complejidad de la gente cotidiana. La temática aborda, asimismo, las relaciones entre los seres humanos, la apariencia que no se corresponde con las realidades personales, las mentiras que las personas se hacen a ellas mismas, las verdades dichas y las ocultas, el orgullo y los prejuicios. De alguna manera denuncia la agresividad, la humillación y la violencia soterrada que se esconde en algunas situaciones socioemocionales, y que se ejerce por medio de las palabras, del poder y de las preconcepciones intelectuales.

Las películas de Agnes Jaoui tratan también sobre las clases sociales, puesto que son comedias dramáticas pro- tagonizadas por personajes burgueses cotidianos, basados en un entorno con el que está muy familiarizada, por lo que se puede permitir el lujo de retratar personajes a los que conoce. Dentro de esta estructura social denuncia la hipocresía y las normas sociales, unas veces impuestas por la familia, otras por el medio al que pertenecemos (como el medio intelectual en Le goût), etc. Normalmente muestra un estrato social medio 0 alto que comparten los personajes, aunque sus edades oscilan entre los 20 o 30 años y la cincuentena. De hecho, una de sus inquietudes es el paso a la madurez, porque aunque socialmente es una etapa de llegada, de estabilidad, de recogida de los frutos de la juventud, la realidad cuestiona estas premisas en muchos de sus personajes, provocando resignación o rebeldía.

Como no podía ser de otra forma, sus historias se centran en las relaciones interpersonales que se forjan entre las múltiples y diversas personas que aparecen en cada historia, ninguna más importante que otra. Entre ellas se establecen relaciones de amistad, a veces por conveniencia y a veces no, en ocasiones beneficiosas y en otras no. No puede dejar de lado, por tanto, las relaciones de pareja, un tema central sobre el que se cuestiona a menudo, pues alude a la cotidianidad impuesta según las reglas sociales, a la monotonía o al adulterio.

En cuanto a las relaciones personales, otra preocupación constante de Jaoui es la falta de escucha y la incomunicación. Resulta curioso, en este sentido, la recurrencia de algunas cineastas al tema de los malos entendidos, los mensajes que no llegan y la inexactitud de las palabras: la directora española Isabel Coixet, por ejemplo, en películas como Cosas que nunca te dije (1995) o en La vida secreta de las palabras (2005) habla de "todas esas palabras perdidas, que durante mucho tiempo vagan en un limbo de silencio (y malentendidos y errores y pasado y dolor) y un día salen a borbotones y cuando empiezan a salir ya nada puede pararlas" (Cerrato, 2008, 143). Entre el cine de ambas directoras pueden encontrarse analogías en cuanto a la importancia que conceden al lenguaje verbal y no verbal, al juego de expresiones y a la comunicación gestual, en silencio. Además, Jaoui reflexiona sobre el lenguaje en sí mismo, o sobre las palabras dichas sin pensar que causan dolor; pero, más allá de las formas, nos da a entender que la razón principal de la incomunicación es la incapacidad para ponerse en el lugar del otro. En este punto la interpretación de los actores es esencial, y de hecho muchos de 
los intérpretes elegidos por la directora francesa provienen del teatro, como es el caso de una de las protagonistas de Le goût des autres, Anne Alvaro (Clara).

En la misma línea, la queja extraída de todas sus producciones reside en la incapacidad de la sociedad francesa para expresar afectividad. Por tanto, siempre aparece latente una afectividad no dicha, un miedo a la expresión de sentimientos, una reticencia a mostrarse tal como uno siente. En este punto es obligada la referencia a Jane Austen, autora de la que Agnès se confiesa admiradora: "Todas mis películas podian perfectamente titularse OrguIlo y prejuicio, en homenaje a Jane Austen, una autora a la que adoro" ("Agnès Jaoui: Me fío mucho de mí misma como actriz"). Efectivamente, Orgullo y prejuicio y Sentido y sensibilidad de Austen y otros títulos como La edad de la inocencia de Edith Wharton, ya abordaron, igual que nuestra autora, la imposibilidad de expresar sentimientos, así como las contradicciones y apariencias de las altas clases sociales, el juicio social, la falsa honra y la moral, y el rol de las mujeres en la estructura social.

No obstante, a pesar de la contundencia y profundidad de las temáticas, el carácter de las películas firmadas por la directora gala es siempre distendido, incluyéndose en lo que podríamos llamar comedia dramática. Por medio de un humor ácido y mordaz retrata personajes controvertidos y realiza una crítica aparentemente leve, sutil. Esta ligereza, cercana a la narrativa del cine popular, le permite realizar un cine que retrata la realidad de forma agria pero siempre transmite una visión esperanzada.

En efecto, estas películas suelen plantear "moraleja": la posibilidad del cambio y la reinvención personal. "Siempre procuramos que al menos dos de los personajes de las películas cambien, tengan una esperanza en el futuro" ("Agnès Jaoui aborda el feminismo en tono de comedia en Háblame de la lluvia"), afirma Jaoui, mientras otros personajes permanecen estáticos en sus elecciones vitales. El pasado de los personajes resulta siempre determinante en este sentido, puesto que la educación y las circunstancias familiares previas condicionan el presente y, para esta autora, la libertad en la que vivimos en la sociedad actual es aparente porque todos arrastramos nuestro propio pasado, "existen todavía unos arraigados prejuicios y herencias del pasado difíciles de desempolvar" ("Agnès Jaoui: Me fío mucho de mí misma como actriz"). Pero siempre permite un espacio para el cambio y el tránsito, para la ruptura de estereotipos $y$, en la mayoría de los casos, los personajes llegan a tener un mejor conocimiento de sí mismos. En esta mezcla de escepticismo y cierta dosis de pesimismo, invariablemente deja una puerta abierta, una apuesta por los personajes que deciden renunciar a las normas impuestas y realizar un cambio en su vida para obtener un triunfo emocional.

\section{Para todos los gustos. Falsas apariencias}

Le goût des autres presenta a diversos personajes en torno a un rico -aunque poco instruido y algo patán- industrial, Castella (Jean-Pierre Bacri). Para cerrar un importante negocio se ve en la obligación de aceptar durante un tiempo la compañia de un chófer y un guardaespaldas personales, así como de recibir clases de inglés de Clara (Anna Alvaro). Clara, quien resulta ser la actriz principal en la obra de teatro en que aparece su sobrina, es una actriz en continuo conflicto interior, amparada por su grupo de amigos intelectuales, y censuradora de la trivialidad. A su vez, es amiga de una camarera, Manie (Agnès Jaoui), dos artistas, Benoît y Antoine, y para cerrar el elenco intervienen en la cinta Angélique, mujer de Castella que se dedica a la decoración, y su hermana. Se mezclan, por tanto, distintos estratos sociales, gustos y entornos vitales. El interés no correspondido hacia su profesora de inglés despierta en Castella el gusto por el teatro y el arte, y produce un cambio en su forma de vida: intenta introducirse en el círculo de "artistas", que lo observan con curiosidad y mofa, se interesa por el arte abstracto, rechaza las costumbres y los gustos de su cursi mujer, y se cuestiona sobre su propia existencia. Todos estos hechos y otros muchos permiten a Jaoui mostrar lo dañino de los prejuicios, las barreras culturales y los fundamentalismos de las escenas sociales cerradas en torno a sí mismas, así como la dificultad de acceder a un medio que no es propio.

El teatro y las artes son fundamentales en las obras de Agnès Jaoui. En todas sus películas tiene lugar una referencia explícita a diferentes artes; es más, a menudo la ambientación de sus historias se ve enclavada en los entresijos de las producciones artísticas (espectáculos, conciertos). En primer lugar porque los conoce bien, y en segundo porque, si bien los ambientes del mundo del teatro, la música y las artes plásticas resultan extraños y elitistas para aquellos 
que no los frecuenten, a ella le sirven para hablar de las hipocresías y de las durezas personales de ese mundo aparentemente exitoso.

Concretamente Le goût des autres es un homenaje al teatro, pues desvela los entresijos del ambiente teatral, y deja patente que Jaoui es incapaz de deshacerse de su faceta de actriz y autora teatral. El teatro cumple también la función de marco en la historia, que comienza con Bérénice de Racine y cierra con Hedda Gabler de Henrik Ibsen, y es el medio transformador a través del cual se desvelan las falsas apariencias y se desdibujan las fronteras entre el actor y el espectador de la vida real.

La intelectualidad, por tanto, aparece como un gueto social. Se sitúa en paralelo con otras imposiciones actuales como son la imagen y el poder que aporta el dinero en la sociedad capitalista. Contrasta, precisamente, el papel que desempeña Bacri en Le goût des autresy el que hace en Comme une image, pues en una es un hombre rico pero inculto, y por tanto despreciado, mientras en la otra es una persona déspota y vanidosa pero respetada por su profesión de escritor reconocido. No es la primera vez que Jaoui caricaturiza la intelectualidad: ya en On connaît la chanson, el personaje que ella misma representa está realizando eternamente una tesis doctoral sobre "Los caballeros campesinos del lago de Paladru en el año mil", tema apasionante donde los haya para la doctoranda pero que no consigue sino poner en tela de juicio los extremos intelectuales y parodiar la investigación. Igualmente, todos los personajes están muy marcados por sus profesiones, puesto que lo profesional establece jerarquias que determinan su carácter, su pensamiento, su clase social, su nivel de estudios y, consecuentemente, la opinión de cada uno es valorada en función de su profesión y su éxito profesional. Por ejemplo, para Clara tendrá más entidad lo que opinen de la obra de teatro sus amigos que lo que opine Castella, o para Pierre, escritor frustrado de Comme une image, tendrá más relevancia la opinión sobre su obra del consagrado Cassard que la de su mujer o su editora. Así, igual que con el tema del arte, puede leerse entre líneas que la postura de Jaoui nos advierte que para apreciar el arte, o para valorar la competencia de las personas, no es necesaria una talla intelectual determinada sino una actitud y apertura sensitiva.

En definitiva, Le goût des autres es una película sobre los prejuicios. Castella no se imagina que Benoit y Antoine sean homosexuales, igual que Clara no se imagina que Castella pueda tener gusto por el arte, de la misma manera que a Angélique no se le ocurre que a su marido o a su hermana le pueda gustar otro tipo de estética que no sea la suya. Los estereotipos formados aparecen muy claros en la conversación que Castella mantiene con su estirado y brillante asistente, Weber, cuando éste le presenta su dimisión: "Usted me ha juzgado desde el principio, porque yo no formo parte de su mundo", le dice Weber, a lo que Castella responde: "Yo pensé que era usted el que me despreciaba... Discúlpeme si le he hecho daño... no me daba cuenta".

\section{Como una IMAGEN. LA VOZ Y LA IMAGEN}

Su segunda película como directora, Comme une image, es más dramática que la anterior y la siguiente, que son comedias. Trata la falta de confianza en sí misma de una estudiante de canto, Lolita Cassard (Marilou Berry), una joven de veinte años cuyo aspecto físico, lejos de acercarse al del personaje de la novela, está fuera de los cánones establecidos; desearía parecerse algo más a la hermosa mujer de su padre, Karine, al menos para que éste le hiciese más caso. Su padre, Etienne Cassard (Jean-Pierre Bacri), es un novelista reputado y egocéntrico que solo se preocupa de sí mismo y del avance de su edad. Basándose en la propia experiencia, la historia establece la reflexión sobre la relación padre-hija y las vivencias de la hija cuando el padre tiene una novia de su misma edad. La profesora de canto, Sylvia Millet (Agnès Jaoui), es una de las admiradoras del famoso escritor e intenta conocerlo para beneficiar a su marido, Pierre Millet (Laurent Grevill), un novelista en ciernes, descreído del talento y el éxito, pero ella misma duda de sus capacidades y de las de su alumna. Además de otros personajes, también entra en escena Mathieu, del que está enamorada Lolita, y Sébastien, un joven recién salido de la carrera de periodismo que a su vez se enamora de Lolita.

En este caso los escenarios artísticos que circunda la película son el de la música y el de la literatura: el ámbito de la literatura no solo en cuanto a la creación, sino retratando el ambiente del mundo editorial con sus condicionantes. $Y$ el ámbito de la música puesto que aparece el estudio del canto, el conservatorio de música $y$, como un personaje más, interviene el conjunto vocal al que pertenecía Jaoui desde tres años atrás y que quería mostrar en la película. 
Asi pues, esta es una película coral más que nunca, en ambos sentidos. Todas sus obras son corales, puesto que muestran una paleta de personajes diferentes, cada uno con su identidad concreta y a la vez en tránsito; por medio del lenguaje, las profesiones o las actitudes, los personajes se presentan en distintos estamentos socioculturales. Al tiempo, son corales porque plantean distintos tipos de relaciones, de implicaciones amorosas, familiares, laborales o interesadas, sin realizar una crítica explícita a ninguna de ellas. Desde las primeras obras teatrales de Jaoui-Bacri se aprecia una evolución, y desde obras sobre un solo tipo de conflicto se pasa a obras corales también en la temática, de manera que se tratan simultáneamente distintas problemáticas. De esta manera, cada una de las "voces" defiende su singularidad, en un reflejo de la sociedad plural. En ocasiones pueden oírse disonancias entre ellas, pero todas conforman la obra total colectiva, sin solistas, de modo que la capacidad de adaptación manteniendo la individualidad resulta fundamental para encontrar la "armonía", es decir, para cohabitar la sociedad.

Comme une image aborda directamente la crítica del culto al cuerpo, al que confronta con la voz. A través del personaje de Lolita denuncia la tiranía de la imagen, la belleza, la juventud que nos venden los medios de comunicación, y en cambio pone de relieve la importancia de la atracción emocional y la búsqueda de la propia "voz". Jaoui relata cómo desde que comenzó en el mundo del teatro a los quince años se dio cuenta de las injusticias que se producian a causa del físico y cómo sentía que a los dieciséis años era demasiado mayor porque en ese momento Sophie Marceau era una estrella de trece. Sin embargo, la voz mejora a medida que se trabaja, y mientras el trabajo personal es individual, depende de uno mismo, la tiranía de la imagen es aleatoria y depende de los demás. De esta manera Jaoui compara el sonido y la imagen, el trabajo de la voz frente a la irrelevancia del físico. Apuesta, por lo tanto, por que cada uno encuentre su propia individualidad, dentro de esa coralidad. Ella misma manifiesta: "Es verdad que cada cual tiene su forma de encontrar el placer, la sexualidad. Es un momento complejo, ni blanco ni negro; las cosas nunca son tan sencillas. Por eso pienso que hay que aprender a considerar que existen diversos modelos de vida, muchas formas de amarse, de crecer, de construir" ("Agnès Jaoui. Conozco tu canción")

El debate sobre la imagen que plantea esta película se refiere también al reflejo de nosotros que se proyecta en los demás. Todos y cada uno de los personajes que aparecen provocan en los demás una serie de reacciones, positivas o negativas, que son motivadas por su comportamiento, y que son como una imagen de ellos mismos. De esta manera, indirectamente, Jaoui toca el tema de la imagen social, el del reconocimiento público por parte de los demás, así como el tema del poder desde el punto de vista de quien lo tolera y las justificaciones ante la falta de resistencia al acatar sus imposiciones. Es más, Jaoui y Bacri pensaron en llamar a la película "Las razones correctas" porque uno siempre encuentra razones para justificarse, hablando de sus necesidades. El éxito, o más bien la falta de éxito, el fracaso, también son planteados continuamente, y concretamente Comme une image deja patente que el éxito o el fracaso social no implican el éxito o fracaso emocional; es más, en numerosas ocasiones el éxito social implica un fracaso emocional (como el escritor y su pareja): en la sociedad actual es importante el dinero y el éxito profesional, pero se deja de lado el éxito emocional y la consecución de la felicidad.

\section{Háblame de La lluvia. Identidades en Conflicto}

Parlez-moi de la pluie debe su nombre a la letra de la canción L'orage de Georges Brassens, que comienza con la letra "parlez-moi de la pluie, et non pas du beau temps". La película transcurre en un agosto lluvioso y tiene como protagonista a Agathe Villanova (Agnés Jaoui), una feminista involucrada en la política que vuelve desde Paris a su pequeño pueblo del sur de Francia para vender la casa tras la muerte de su madre viuda. La acompaña su pareja, Guillaume (Laurent Jarroir). Allí, en la casa en la que ha crecido, se topa con sus recuerdos. Intervienen en la historia otros personajes como la asistenta argelina de la familia, Mimouna (Mimouna Hadji), su hijo Karim (Jamel Debbouze) y un amigo de éste, Michel (Jean-Pierre Bacri), un cineasta divorciado con el que quiere hacer un documental sobre ella para una serie sobre mujeres con éxito. Su hermana Florence (Pascale Arbillot), casada y opuesta a ella en todos los aspectos, mantiene una aventura con Michel.

Los conflictos derivados de estas interacciones pondrán en tela de juicio la relación de pareja de Agathe pero, sobre todo, sus principios políticos, puesto que uno de 
los propósitos de la directora era plantear la pérdida de contacto de la política con la realidad. Por eso la protagonista se cuestiona continuamente si sus decisiones son las correctas y si debe mantener sus opiniones aunque sus pensamientos parezcan irrazonables. La trama, por lo tanto, toma derroteros absurdos derivados de malos entendidos en los que, como es habitual en Jaoui-Bacri, todos los personajes parecen cuestionarse sus valores esenciales. Al mismo tiempo, sirve de excusa para tratar el tema de las relaciones de poder que se establecen entre los actores, los sentimientos de inferioridad, la sumisión, la humillación y las jerarquías sobrentendidas, que subyacen en el fondo de la película.

El tono al que ya nos tiene acostumbrados esta autora es ligero y humorístico, con un punto melancólico, pero por detrás se esconde una visión crítica. En este sentido, establece un paralelismo con las películas de Eric Rohmer, aparte de por la concordancia de personajes realistas en contextos cotidianos, porque, aunque parece que no ocurriera nada, imperceptiblemente va narrando los caminos internos que siguen los personajes consigo mismos y en su relación con los demás. En Parlez-moi de la pluie, como en el resto de sus películas, da la impresión de no estar pasando nada trascendente ni dramático, todo es aparentemente inocuo, pero cada hecho, cada diálogo, cada mirada, son determinantes para hacer avanzar progresivamente la acción hacia un pequeño drama vital.

Dado que el personaje de Agathe está implicado políticamente con el feminismo, el tema se presenta más candente que nunca en esta película. Constituye una cuestión cercana para nuestra autora porque la madre de Jaoui era feminista, así que en su casa había muchos libros sobre el tema; lo que se encontró en ellos, sin embargo, no era lo que esperaba sino, según refiere, "un gran odio hacia los hombres" ("Agnès Jaoui aborda el feminismo en tono de comedia en Háblame de la lluvia"). Por esa razón, la postura de Agnès Jaoui al respecto huye de los extremos, y en esta historia hace una dura crítica al victimismo, concretamente a través de la crítica al feminismo que se ha refugiado en dicho victimismo. Prefiere situarse en una postura intermedia: "Ahora el feminismo ha evolucionado hacia otro punto, pero muchas mujeres continúan sintiéndose culpables cuando dejan a un lado sus responsabilidades para dedicarse un poco de tiempo, e incluso existen otras que creen que los hombres son una amenaza para su felicidad", añade ("Agnès Jaoui aborda el feminismo en tono de comedia en Háblame de la lluvia").

A pesar de que su mirada no promueve manifiestamente una perspectiva de género, ni trata exclusivamente personajes femeninos, son muy abundantes en su cine conflictos derivados de la problemática social que sufren las mujeres a causa del patriarcado. Resulta lógico si pensamos que muchos de los personajes que describe Jaoui muestran una falta de consecución de sus deseos, son personas que actúan en contra de lo que quieren o tienen que adecuarse a los estereotipos que se les imponen. Los roles tradicionalmente asignados a las mujeres son un caso evidente, por eso las películas ponen de manifiesto lo dura que resulta aún la sociedad del siglo XXI para las mujeres a causa de las normas éticas y sociales. Así, encontramos en Le goût del autres una Clara con miedo a envejecer, y a envejecer sola, y una Manie cuya forma de vida solitaria implica prejuicios sociales: ellas mismas se cuestionan si deberian poner un hombre en sus vidas para formar una familia. Encontramos, asimismo, una mujer dependiente socialmente de su marido, Castella, con el que ya no tiene nada en común, y una hermana que debe soportar los compromisos familiares por no tener un compañero a su lado. Resulta curioso si reparamos en que la película, como ya se señaló, comienza con la representación de Bérénice, mujer oprimida por su condición, y termina con Hedda Gabler, que se suicida antes de conformarse con su vida de casada. ${ }^{1}$ En Comme une image salta a la vista la dictadura que sufre Lolita a causa de su aspecto físico, pero tampoco resulta agradable el personaje objetualizado de Karine o las inseguridades de Sylvia cuando su marido triunfa, como tampoco es cómodo el papel de la inmigrante Mimouna o el de la frustrada Florence de Parlez-moi de la pluie.

A lo largo de estas tres películas pueden observarse grupos sociales plurales, formados por individuos diversos, cada uno de los cuales muestra sus propios rasgos. El conjunto de estos individuos revela al espectador una identidad colectiva, pero al mismo tiempo plantea la cuestión de la definición de la identidad. El tema de la sociedad multicultural, multi-racial, multi-religiosa, etc. es una realidad de rabiosa actualidad en Francia, por eso es una cuestión sobre la que es necesario reflexionar y que en esta película se pone de manifiesto más que nunca a través de los caracteres de Mimouna y de Karim. Se intuye también en Comme une image, cuando Sébastien confiesa a Lolita que 
se llama Rachid, pero que ocultar su verdadero nombre le hace el día a día más fácil.

La presencia de personajes desubicados pone al descubierto la cuestión de la identidad de la propia Jaoui, derivada de cierto sentimiento de alienación y sus propios conflictos personales con la identidad judía o burguesa. Así se expresa nuestra autora en este sentido: "Detesto las mono-culturas. El problema de la identidad es algo muy complicado para mí. Soy profundamente secular, pero si fuese atacada por ser judía, gritaría. Y quiero el derecho a decir que condeno violentamente las políticas de Ariel Sharon, por muy complejo que sea" ("The Taste of Others"). E igualmente afirmaba en un periódico: "Me siento judía cuando se ataca a los judíos, árabe cuando se los ataca, feminista contra el sexismo. Creo que una identidad es muy importante, que debe preservarse, que debe poder expresarse sin encerrarse nunca" ("Agnès Jaoui. Conozco tu canción").

Algo parecido opina su colaborador Jean-Pierre, quien es hijo de un cartero de Cannes proveniente de Argelia. Para ambos, lo importante es la individualidad; todas sus obras son una defensa de la individualidad, una crítica acérrima al fundamentalismo de los grupos cerrados, sean del tipo que sean, y un canto a la tolerancia. Si la barrera de las diferencias culturales puede romperse, el individuo también debe ser capaz de superar las creadas por cuestiones de herencias, raices o tribus.

\section{LA MÚSICA EN JAOUI}

Hasta ahora se ha demostrado el lazo de unión que establece Agnès Jaoui con la música, pues sin duda constituye una de sus armas creativas fundamentales. En los últimos años, además, se ha convertido en su segunda profesión. No resulta extraño sabiendo que la música ha sido una presencia constante en su vida, desde que en su casa de infancia escuchara ópera y la canción popular francesa de Brassens y Mouloudji. Con quince años comenzó una relación directa con la música estudiando canto clásico y barroco en el Conservatorio del 7ème arrondissement de Paris y después en el de Enghien. Esta cercanía le permite relatar los ambientes de la música clásica con cotidianidad y naturalidad: vemos en sus obras a personas estudiando un instrumento, ensayando; aparecen grupos de músicos amateurs y las relaciones entre sus miembros, lo que contribuye a desmitificar el mundo de la música clásica. Ella misma se muestra cantando en Un air de famille, donde interpreta "Come Prima" de Dalida; en Le rôle de sa vie canta un bolero; canta, también, en el musical de Resnais On connait la Chanson y recientemente ha puesto voz en el cortometraje musical de animación Sous un coin de ciel bleu (2009) de Arnaud Demuynck y Cecilia Marreiros Marum. No en vano ya ha afirmado varias veces que su sueño sería dirigir una película musical ("Entrevista a la directora francesa Agnès Jaoui").

En 2006 comienza su carrera como cantante con el álbum Canta, que recibió el Premio Victoires de la Musique en la categoría de mejor álbum de World Music en 2007. En él colabora con músicos brasileños, cubanos y peruanos, de manera que incluye géneros musicales que admira, como son fados, bossa nova, bolero y flamenco (bulerías), en canciones en español y portugués, con las que pretende, según dice, interpretar canciones poco conocidas en Francia. Comenta también que las músicas de las películas de Pedro Almodóvar le inspiraron esos sonidos latinos, y se confiesa admiradora de Martirio, Rosario y también de Lola Flores ("Agnès Jaoui"). Su segundo álbum, Dans mon pays, con El Quintet Oficial y producido por Vincent Segal, aparece en 2009. En éste canta canciones en español, alguna en portugués y dos canciones en francés (una escrita por ella), así como dúos con Bonga y Camané. Llama la atención cómo en su música expande sus raíces multirraciales, quizá porque con la música es más fácil abordar la multiculturalidad de una manera amable. Así, una cineasta que hace retratos de paisajes personales muy ligados al contexto francés, en la música se deja llevar a otros parajes, se relaja y se permite disfrutar la música en vivo para despegarse de su lado controlador más cinematográfico.

Respecto a la música que aparece en sus películas, tiene mucho que ver con sus gustos particulares, más que responder a funciones estructurales concretas. No obstante, la pluralidad de posturas vitales presentes en sus obras hace que la aparición de géneros musicales muy dispares concuerde muy bien con el resultado filmico total. Entre sus preferencias, la música clásica y en concreto la música barroca son una presencia constante, de manera que no necesita composiciones de música incidental realizadas expresamente. Son, por tanto, elecciones estéticas, que 
nacen durante el proceso creativo de las películas. En Le goût des autres aún no había definido el papel de la música y al preguntársele cómo elegía los distintos tipos de música, responde que algunas ya estaban presentes en la creación del guión pero que otras fueron surgiendo en el momento del rodaje ("Para todos los gustos. Notas de la directora Agnes Jaoui").

Comme une image establece el propósito determinado de recrear la emoción de la música en vivo. De hecho, llegó a entrar en conflicto con los ingenieros de sonido que pretendian suprimir las imperfecciones, mientras ella se empeñó en mantenerlas porque son el elemento que consigue transmitir la emoción del directo. Por eso en la película utiliza siempre que es posible sonido directo y todos los músicos cantan en vivo (salvo la protagonista). En este caso todas las piezas estaban elegidas con anterioridad para intervenir diegéticamente, así que recurrió a piezas familiares para ella.

Narrativamente, la música también cumple un papel primordial porque el trabajo con la voz, con el canto, se convierte en una perfecta metáfora del camino en la búsqueda de la propia individualidad, de afirmación de las opiniones y las decisiones propias. Así, Lolita no es capaz de cantar en presencia de su padre, que la intimida y la asusta, pero en cambio sí puede hacer un dúo con Sébastien, con el que se siente a gusto. La escena final en la que Lolita interpreta a pleno pulmón An die Musik de Schubert supone la conquista de su idiosincrasia y el descubrimiento de su propio camino.

Otra hermosa analogía musical se halla en Le goût des autres, donde Moreno, el chófer, aprende a tocar la flauta. Aunque en la película no es uno de los personajes con más suerte (su novia le abandona por carta desde Estados Unidos), sirve para cerrar el filme en un guiño tierno a la continuación de la vida. Durante toda la película le vemos dando sus primeros pasos con el instrumento, primero muy torpemente, luego algo más rápido, haciendo un obstinato rítmico continuo sobre una sola nota. En la escena final escuchamos ese ritmo repetitivo y monótono que toca en su flauta, pero cuando se abre el plano vemos que forma parte de una agrupación musical de vientos que tocan una versión del "Je ne regrete rien" de Edith Piaf. La estructura rítmica es la base, sencilla pero necesaria, para que esa música se sostenga. Un final esperanzador que resume perfectamente una película donde se pone de relieve la necesidad de cada individuo de encontrar su voz dentro de una comunidad, su individualidad dentro del todo, como dice la canción, sin arrepentirse de nada.

De una forma u otra, las películas de Agnès Joaui consiguen sutilmente su propósito de ser una llamada de atención al espectador. Dando pie a la reflexión sobre la necesidad de ponerse en el lugar del otro, de cambiar y aprender de otros mediante un mejor conocimiento de uno mismo, permiten al público convertirse en otras personas en un ejercicio de tolerancia.

\section{NOTAS}

1 Lo mismo opina Anabel González Moya (2008) en su tesis Agnès Jaoui: un ejemplo contemporáneo de intertextualidad cinematográfica y teatral.

\section{BIBLIOGRAFÍA}

"Agnès Jaoui aborda el feminismo en tono de comedia en Háblame de la Iluvia". La vanguardia.es. Disponible en: http://www.lavanguardia.com/ cultura/20090218/53642865193/ag- nes-jaoui-aborda-el-feminismo-entono-de-comedia-en-hablame-dela-lluvia.html. Consulta: 24/04/2011.

"Agnès Jaoui. Conozco tu canción". Lanacion. com. Disponible en: http://www.lanacion.com.ar/916811-agn\%C3\%A8sjaoui-conozco-tu-cancion. Consulta: 24/04/2011.

"Agnès Jaoui: Me fío mucho de mí misma como actriz". El País.com (27/02/ 2009). Disponible en: http://www. elpais.com/articulo/cultura/Agnes/Jaoui/fio/mucho/misma/actriz/ elpepucul/20090227elpepucul_7/Tes. Consulta: 24/04/2011.
Fecha de recepción: 30 de abril Fecha de admisión: 30 de mayo 
"Agnès Jaoui". Producciones animadas. Disponible en: http://www.musikaze. com/es/musica/management/artista. php?cod $=665 \&$ cat $=112 \& \&$ band $=878$. Consulta: 15/02/2011.

Austen, Jane (1811): Sentido y sensibilidad, Barcelona, Debolsillo, 2009.

Austen, Jane (1813): Orgullo y prejuicio, Madrid, Alianza Editorial, 2006.

Ayckbourn, Alan (1985): Intimate Exchanges, New York, Samuel French.

Cerrato, Rafael (2008): Isabel Coixet, Madrid, Ediciones JC.

Eleftheriotis, Dimitris (2001): Popular Cinemas of Europe, New York, Continuum.

"Entrevista a la directora francesa Agnès Jaoui: 'Muchas veces no nos conocemos ni a nosotros mismos'". Blog Pasión por el cine (25/02/2009). Disponible en: http://pasionporelcine.es/ page/155/. Consulta: 24/04/2011.

González Moya, Anabel (2008): Agnès Jaoui : un ejemplo contemporáneo de intertextualidad cinematográfica $y$ teatral, Tesis doctoral, Universitat de València, Servei de Publicacions.

Ibsen, Henrik (1890): Hedda Gabler, New York, Dover, 1990.

Jaoui, Agnès y Jean-Pierre Bacri (1991): Cuisine et dépendances, Paris, L'AvantScène Théâtre, 2005.

Jaoui, Agnès y Jean-Pierre Bacri (1994): Un air de famille, Paris, L'Avant-Scène Théâtre, 2005.
"La francesa Agnès Jaoui estrena el viernes Para todos los gustos". El cultural.es (15/11/2000). Disponible en: http://www.elcultural.es/version_ papel/CINE/12968/La_francesa_ Agn\%EF\%BF\%BDs_Jaoui_estrena_ el_viernes_Para_todos_los_gustos. Consulta: 30/05/2011.

"Para todos los gustos. Notas de la directora Agnes Jaoui". Disponible en: http:// www.filmin.es/blog/para-todos-losgustos-notas-de-la-directora-angsjaoui. Consulta: 14/03/2011.

Pinter, Harold (1958): The Birthday Party, London, Faber and Faber, 1991.

Racine, Jean (1935): Bérénice, Paris, Hachette.

"The Taste of Others". Disponible en:_http:// en.wikipedia.org/wiki/The_Taste_of Others. Consulta: 24/04/2011.

Wharton, Edith (1920): La edad de la inocencia, Barcelona, Tusquets, 1995.

\section{FILMOGRAFÍA}

24 heures de la vie d'une femme (Dir. Laurent Bouhnik, 2002).

Canti (Dir. Manuel Pradal, 1991).

Comme une image (Dir. Agnès Jaoui, 2004).

Contes des quatre saisons (Dir. Éric Rhomer, 1990-1998).

Conte de printemps (Dir. Éric Rhomer, 1990). Conte d'hiver (Dir. Éric Rhomer, 1992).
Conte d'été (Dir. Éric Rhomer, 1996).

Conte d'automne (Dir. Éric Rhomer, 1998).

Cosas que nunca te dije (Dir. Isabel Coixet, 1995).

Cuisine et dépendances (Dir. Philippe Muy, 1993).

Hôtel de France (Dir. Patrice Chéreau, 1987).

La maison de Nina (Dir. Richard Dembo, 2005).

La méthode (Dir. Thomas Béguin, 1997).

La vida secreta de las palabras (Dir. Isabel Coixet, 2005).

Le cousin (Dir. Alain Corneau, 1998).

Le déménagement (Dir. Olivier Doran, 1997).

Le faucon (Dir. Paul Boujenah, 1983).

Le goût des autres (Dir. Agnès Jaoui, 2000).

Le rôle de sa vie (Dir. François Favrat, 2004).

On connaît la Chanson (Dir. Alain Resnais, 1997).

On the Run (Dir. Bruno de Almeida, 1999).

Parlez-moi de la pluie (Dir. Agnès Jaoui, 2008).

Smoking / No smoking (Dir. Alain Resnais, 1993).

Sous un coin de ciel bleu (Dir. Arnaud Demuynck - Cecilia Marreiros Marum, 2009).

Todos dicen I Love You (Dir. Woody Allen, 1996).

Un air de famille (Dir. Cédric Klapisch, 1996).

Une femme d'extérieur (Dir. Christophe Blanc, 1999). 